Milena Vučinić

UDC: 336.01

005.311 .6

\title{
Behavioural Finance and Its Postulates
}

DOI:10.7595/management.fon.2016.0020

The reasons for dealing with the chosen topic can be found in the fact that there is a certain number of anomalies, system errors and conduct leaving the frames of rational behaviour, not being included and presented synthetically within a concise scientific work. Instead, the analysis deals with definite, already identified postulates of behavioural economics and finance. During the research, induction, deduction, comparative and abstraction methods are used. The challenge of the research lies in the identification of those system errors, partialities and behaviours deviating from postulates of rational, typical for classical finance, not being covered by standard behavioural, economic and finance literature. However, the challenge is even bigger because of the fact that it deals with answers to demands of universality and conciseness. Its greatest importance is reflected in the extent of identified and processed anomalies decision makers face, as well as in the identification and description of factors implying absence of rationality during the decision making process.

Keywords: behavioural economics, bihevioural finance, decision making, system errors, anomalies, partialities.

\section{Introduction}

Behavioural finance deals with the influence of psychological factors on the behaviour of individuals who make decisions in the field of finance and consequences such a behaviour causes on the market (Sewell, 2010). Its most important contribution to finance and economics reflects on its help while determining the reasons responsible for inefficient markets, and while defining ways this inefficiency is specified.

The classical finance theory treats all market participants as rational individuals making their decisions in order to maximize their personal financial benefits. However, practice has shown that there are a big number of cases where emotions and psychology influence the decision making process, pointing out that decision makers behave unpredictably, sometimes even irrationally.

Behavioural finance is a relatively new scientific discipline based on the combination of behavioural and cognitive psychological theories, on the one hand, and conventional economics and finance, on the other. The latter has the task to explain the reasons responsible for irrational financial decisions some people make (Hellmann, 2016).

The literature that deals with the problems of behavioural finance can be divided into two main areas: identification of anomalies in the hypotheses that classical market theories are based on (Bondt \& Thaler, 1985) and identification of behaviour of individual investors or their preferences which are not in accordance with classical economic theories of rational behaviour (Odean, 1999). With its approach behavioural finance sets a challenge for the prospect of efficient markets, putting an accent on the ways in which investors interpret information at their disposal. It enables a better understanding of investors' behaviour and events taking place on financial markets. The use of behavioural finance helps investors make better decisions concerning their investments on financial markets that are becoming more complex and challenging.

Behavioural researchers Barberis and Thaler have defined the behavioural finance research direction as follows: "We have now started with the important job of recording and understanding how investors, both amateurs and professionals, make their decisions while choosing their portfolio. Until recently such researches were absent from the toolbox of financial economists, perhaps due to the mistaken belief that asset value can be defined without any knowledge about elements of behavioural economics" (Barberis \& Thaller, 2003). 
The previous starting points in this work can be summarized as follows: the focus is mainly on partiality and irrationality of decision making individuals. The subject, which determines the direction of the research and analysis, can only ostensibly induce readers to think that the idea of financial participants being exceptionally rational represents the author's attitude. However, it is not the case. Most of the attitudes and activities undertaken by individuals are upstanding. Market participants predominantly behave acting and living, taking advantage of impressions and feelings, while trust in their intuitive judgements and propensities in most cases will be justifiable. Yet, the analysis, decomposed through various smaller thematic statements in this work, leads to the conclusion that it is not always the case.

System errors typical of financial market participants relate to partialities and appear if definite conditions are met. Although humans are not aware of it, their mind is permeated with mental processes taking place in silence and consequently, and these processes lead to impressions, intuitive judgements and various decisions.

Bihevioural authors in economics and finance have systematized some knowledge. However, some new knowledge that leads to deviations from the rational in the decision making process is not systematized, so the aim of this work is to obtain as much systematization as possible. Behavioural economics as a scientific discipline tends to explain everything that traditional economics has not explained using the knowledge of social psychology and economics. One of its goals is to point to some constraints of traditional economics as well. According to Anger and Loewenstein (2007), behavioural economics deals with "the manner with which emotions and structure of human mindset influence the decision making process". (p. 64)

According to Todorović (2011), behavioural finance "strives to add some cognitive psychological elements, based on observation and examination of conduct of investors and managers, using sophisticated mathematical-statistical models of modern corporal finance". (p. 5) As such, they warn and point to the fact that mathematical techniques and models applied in finance and economics should be made different from the techniques and models formed in physics, or other natural sciences.

\section{Pillars of Behavioural Finance}

In accordance with the theory of limited arbitrage it is said that in case when irrational traders cause deviations of fundamental value, the fortune of rational traders lies in their helplessness to do anything about that. Aiming to explain the structure of deviation better, behavioural models often assume specific forms of irrationality. The crucial component of any kind of finance market models is the specification of methods on which financial agents form their expectations. What follows below is the summarization of psychological researches on forming attitudes and beliefs in practice.

Excessive self-confidence. There is a lot of evidence that humans evince excessive self-confidence while forming their attitudes. Two cases are significant: the first one is a rather narrow interval of trust people assign to their assessments. The second characteristic is the fact that people are not predestined to assess the probability of events. Thus, when people think some events are certain to happen, they in fact happen in $80 \%$ of cases. On the other hand, events they consider to be impossible, happen in $20 \%$ of cases.

Optimism and "wishful thinking". In most cases people will give voice to unreal viewpoints concerning their abilities and perspectives. Generally speaking, according to Tvede (2005), more than $90 \%$ of people consider themselves above average, especially in terms of skills such as driving, social abilities, creating good relations with others or having a good sense of humour. Big misapprehensions occur while planning, because people often believe that a project will have been finished in the future long before it is really completed.

Representativeness. Kahneman and Twersky have explained the representativeness principle as strategies individuals use during cognitive processes aimed to solve a problem. On the basis of our previous experiences, knowing that events that occur often are more likely to happen than events that occur rarely, we choose the option we consider is more likely to take place.

Kahneman and Twersky have shown that in case when people are trying to determine the probability that data $A$ are defined on the basis of model $B$, or that the object $A$ belongs to the class $B$, people often use the 
representativeness heuristics (Frankfurter and McGoun, 2000). It means that they determine the probability having in mind the extent by which $A$ reflects the essential characteristics of $B$. In most cases representativeness can be of some assistance, but it often influences the forming of certain partialities in the assessment process.

Sticking to beliefs. A great deal of evidence has shown that people, once they form their opinion, stick to it persistently. Two effects are concerned. Firstly, people are not willing to look for the evidence contradicting their attitudes. Secondly, if they find such evidence, they are still sceptical.

In some studies even stronger effects known as confirmation partiality have been found, where people misinterpret the evidence against their hypothesis, wrongly claiming that the evidence supports it. Within the context of academic finance sticking to beliefs is manifested in a simple way, i.e., people who believe in $\mathrm{EMH}$ will continue to do so long after some evidence against it appears.

Affiliation. Kahneman and Twersky claim that, once people form their assessments, they often start the process with some initial, possibly arbitrary number or value, slowly adjusting it and modifying the value. Experimental proofs often show that these variations are insufficient. In other words, people "affiliate" the initial value in their mind and contribute too much importance to it (Ariely, 2008).

Partiality of availability. While judging the probability of an event, people often search for their memories looking for relevant pieces of information. Although it is a completely rational procedure, it can cause partiality in assessing because not all reminiscences are equally "available".

Financial experts are quite careful in accepting experimental proofs because they believe: 1) that, by repeating, people will learn to distance themselves from partionalities; 2) that experts in the field, such as marketeers, will make fewer mistakes, and 3) that, due to strong incentives, these effects will disappear

\section{Making Offers and the Winner's Curse}

Stock exchange processes are part of auctions where excessive prices are paid. When some companies buy other firms, a system error called the winner's curse takes place. In more than $50 \%$ of those transactions, it turns out that new investments do not bring the buyer as much money as he has invested, which means that the purchase has not been profitable at all (Dobelli, 2013).

\section{Aversion to Loss and Sunk Cost Fallacy in Function of Additional Waste of Money by Financial Decision Makers}

In the decision making process, awareness of this fallacy enables decision makers to make sure not to rely on previous costs or price that an investment or security buying (the price they have been bought at) has had, but to take into account only the relevant future costs. Or, the principle refers to the fact that, according to Dobelli (2013), people "should treat the problem equally, having in mind risks they are exposed to, regardless of whether they obtained something for free or purchased it. It is irrelevant for the risk" (p.67). It is emphasized that this is not a mere hypothetical thinking, but the whole series of studies and experiments leading to the same conclusion. ${ }^{1}$ Traditional theory suggests that economic actors should take into consideration only the future costs.

On the other hand, Dobelli (2013) points out that "in the finacial sphere this phenomenon results with an individual's willingness to take bigger risks if it means avoiding certain loss, or bigger investment conservatism when having a chance to obtain earnings". At the same time, this explains the situation when

${ }^{1}$ One of the examples supporting this theory can be found in a study titled "The Psychology of Sunk Cost", published in the magazine Organisational Behaviour and Human Processes", by Hal R. Arkes and Catherine Blumer. 
downtrend shares are retained, and those with better prospects are sold. Long-termed, aversion to loss worsens an individual's financial situation, if it is his landmark decision. The best way to lessen the risk of investments is to diversify it.

\section{Mental Accounting - One Different and One Same Account}

Mental accounting or mental categorization of accounts refers to a special way of formulation which means that people separate some decisions as if they are of completely different categories, even though it is not the case. Namely, an investor can make a decision to take a bigger risk by using resources from an investment account, while having at the same time a special savings account with minimal risk, intended for his child's education. If he were rational, the decision would mean that both accounts are seen as part of his overall portfolio. It also means that properties of both accounts, in terms of risk and profit, would be integrated into a sole framework.

The effect of mental accounting helps in explaining the inertion in share price fluctuations.

On the other hand, the effect of someone else's money refers to the gamblers' willingness to accept new odds, even though they are currently winning. They perceive that with such odds they only risk their winnings, or the casino's money respectively. Since it is not their own money, they are ready to take a bigger risk. Belsky and Gilovich (2002) explain that this "leads to a conclusion that gambling winnings are not considered to be genuine winnings - or it is not the winner's money, anyway the loss is not the real loss" (p.32). This concept has been shaped by Richard Thaler and, according to him, mental accounting is based on, as Belsky and Gilovich point out (2002), "the fact that money is treated differently depending on where it comes from, where it is kept or how it is spent"' (p.32).

\section{The Role of Magical Thinking or "This Action is Lucky"}

Psychologists define magical thinking as a kind of arbitrary behaviour generated with an experience from a situation when one type of behaviour precedes a positive outcome. Here, individuals will repeat that pattern of behaviour, having in mind that they will conclude that there is a connection between their conduct and the very outcome, even though it does not have to be so. Therefore, it has been proven that in case of investment and managerial decisions or behaviour preceding the sale or profit boost, a tendency of repeating the behaviour will appear. It is interesting that in the period of profit boost, when the whole economy gets out of recession, magical thinking reaches its pinnacle, given that companies are alike and observe each other in a similar way. Thus, magical thinking is manifested as a social, not individual phenomenon. Namely, in his hubris hypothesis in corporate acquisitions, Roll (1978) points out that bidder company managers often show excessive self-confidence while assessing other companies, mainly due to their luck in initial acquisitions.

\section{Quasi Magical Thinking}

Shaffir and Tversky are the first ones to talk about quasi magical thinking (1992), explaining the cases in which people believe that something they will do later can change the outcome of what is determined in advance, i.e., they behave as if they can affect the past. Quattrone and Tversky wrote about that as well (1984). Experiments show the trend of self-deception. It is interesting that quasi magical thinking is mainly manifested in situations with outcomes of future events, rather than historical ones. Langer (1975) draws attention to the fact that individuals are willing to invest more money in tossing a coin odds, i.e., the scenario when the coin is not tossed yet, unlike the scenario when it has been already tossed. It suggests that they are convinced they can affect the outcome. From the previously mentioned reason, by means of quasi magical thinking, we can explain why people vote in elections or why shareholders use their rights of first refusal while voting for certain decisions. Even the very effect of acquisition can correlate with quasi magical thinking.

Namely, a tendency of holding loss-share assets and sell profit shares is emphasized as a type of quasi magical thinking. Holding shares whose value goes below the value they have been purchased at, is justified by the conviction that, by keeping shares, the fact that the loss has already occurred can be eliminated. 


\section{How Organizational Culture Directs all Management Decisions the Same Way}

Scrutinizing pension fund managers and using personal interviews and anthropological methods, O'Barr and Conley (1992) have concluded that every pension fund has its own culture which can be connected to the various history of origin of their company. This way they find similarities with myths created by primitive people. Namely, the pension fund culture is a system of beliefs in terms of their investment strategy, and this culture manages the investment fund. Cultural factors are significant due to the tendency to transfer the decision making responsibility to the organization and maintain personal connections with the organization. ${ }^{2}$

It means that cultural contamination has got a role of a guideline or landmark during the decision making process, and these decisions neither have objective character nor is their validity based on objectivities a concrete situation abounds with.

\section{Global Culture - Sociological Phenomenon With Economic Consequences}

It is a big challenge to determine which direction global culture effects are taking. Namely, Hannerz (1999) points out that "world culture exists, but we are not aware what it really means. It is marked by the organization of diversity rather than the replica of uniformity... The world has become a social relation network, and in its various regions there is a moving of ideas, people and goods" (p.237). Profound economic implications are found in a study written by Robert Meson, a sociologist, who dealt with the nature of interpersonal effects which resulted in his categorization of people. He came to the conclusion that people can be classified into two categories: locals (they are interested in local news and they derive their status from their connectivity with others) and cosmopolitans (they are oriented to the world news and they derive their status regardless of their community). He also concluded that cosmopolitans have transcendental influence on locals, which means having provisions of useful pieces of information. Global culture can explain why real estate market in many cities all around the world boosted during the late eighties and declined during the early nineties. Therefore, if a global nature of culture exists, there is no reason to link these events with some information concerning the very fundamentals of economics.

\section{The Importance of Irrelevant Information in Decision Making}

Behavioural economists' research has shown that people are mainly incited by irrelevant pieces of information while making decisions. The problem lies in the fact that individuals are not aware of this. A study carried out by Gregory Northcraft and Margaret Neale from Arizona University refers to this trend of managing supporting information. Hereupon, behavioural economists have issued a warning about this. Potentially, there is a problem in decision making on the basis of irrelevant information when someone shows excessive self-confidence while negotiating and bargaining. The same problem occurs when someone makes decisions about consumption and investments based on inconsiderable monitoring.

\section{Authority Bias in the Context of Global Financial Crisis}

This is about the system error described as the authority bias (Dobelli, 2013.), and it represents the practice or trend of respecting authority with almost biblical significance. Or, disrespect of authority presumes some kind of moral, corporal or financial punishment. Due to the authority bias two problems occur. Despite the fact that there are about one million of economists on this planet, none of them predicted the financial crisis. Apart from that, they did not predict that this crisis, together with the real estate market crisis, would cause the disturbance on a global economic level and gain the status of a global crisis. In addition, in the presence of authority, individuals usually express less critical and independent opinions. People show deficiency of

2 In 1972. psychologist Janis documented a series of cases showing that social patterns (groupthink) in decision making process can lead to making catastrophic decisions by highly intelligent people. 
caution while adopting certain attitudes or information, unlike situations when the same information is gained, for example, from an ordinary individual. More serious implications occur due to the fact that one shows obedience to authority, even in a situation where there are not any moral or rational reasons for that. Such behaviour is the essence of this bias. The very financial crisis manifests the authority bias. Having in mind which models have been used in the market liberalization, all financial actors believed that such models could not be faulty. A critical approach was of less quality considering the fact who the creators of this model were.

\section{Decision Making Under Uncertainty - How to Make Decisions When not all Pieces of Information are Available}

Nowadays, a large number of financial decisions are made on the basis of beliefs about a probability of an uncertain outcome such as, for example, the future value of some shares or currencies. In certain cases beliefs about uncertain events are expressed quantitatively as chances or subjective probabilities. Generally speaking, individuals rely on certain limited number of heuristic principles thanks to which complex probability assessment tasks and value predictions are reduced to simple decision making operations. Therefore, heuristics are useful to a certain extent, but can often lead to serious and system errors. We talk about conclusions based on the data with limited reliability, whereby they are processed in accordance with heuristic rules.

For example, the similarity factor is important for representativeness heuristics, often with a certain stereotype. Another heuristics observed refers to the outcome probability. One factor that does not have any consequences for representativess but is expected to create most of the probability consequences, is in fact the prior probability or the so called basic frequency of outcome. When the assessment by means of representativeness is carried out, prior probabilities are neglected in most cases.

People usually rely on the representativeness heuristics with a sample derived from a certain population. The respondents do not take into consideration the sample size when assessing whether similarity between sample statistics and population parameters should exist or not. Therefore, when probabilities are assessed on the basis of representativeness, the sample statistics probability assessment will be independent of the sample size.

\section{Trust as Decision Making Factor}

Financial decision making is affected by trust in the financial system. With a low level of trust loan placement decision makers choose to freeze the loan market, which was the case in 2008. Trust as such is not included into the standard economic and financial theory. Trust in the financial system is always shattered during financial crises.

\section{Fairness as a Decision Making Factor}

Fairness is perhaps as much important as economic motivation economists and financial experts pay much more attention to. However, fairness research shows it is absolutely realistic to expect that taking fairness into consideration would throw the economic motivation back. Experiments about this are very interesting, probably the most important among them being the one carried out by Ernst Fehr and Simon Gachter (2000). Therefore, if individuals are noticed cheating, after a certain longer period everyone becomes selfish. Experiments carried out by Fehr and Gachter have shown that subjects were willing to pay in order to punish bilkers, which also means that subjects paid special attention to fairness.

\section{Stories as Factors that Influence the Economic Behaviour of Individuals}

It is typical of the human mind to be created to think in stories or series of events characterized with their inner logic and dynamics, acting like a whole. The most typical examples of stories affecting the behaviour of individuals in terms of decision making are stories about bank insolvency. Spreading these stories is like a virus, i.e., very fast. These stories lead to a bank bankruptcy because account holders withdraw their deposits. In Rational Exuberance Shiller (2000) reveals the role of the story about using the internet in causing security market boom. 


\title{
15. The Black Swan or the Impact of the Highly Improbable
}

\begin{abstract}
Nassim Taleb is credited with developing the expression black swan (Brunaker, 2013). Namely, in his second book Black Swan: the Impact of the Highly Improbable Taleb (2004) explains the Black swan in detail, based on the three criteria determining it: unpredictability (rarity), extreme impact and retrospective explanation, all of which are pointed out by Brunaker (3013). Firstly, it is about an atypical event having in mind that it is out of usual expectations and regarding the fact that there were no convincing evidence about it in the past. Secondly, it is an effect with extreme impact. Thirdly, despite of its atypical status, the human nature manifests a tendency to explain itself afterwards thus making it predictable, which is a kind of fallacy, as Taleb warns (2009). Nothing from the past can be used to prove the existence of the Black Swan (Estrada, 2009). It is useful to point out that scientific research on rare events, especially in economy, is prevented due to a mechanism known in psychology as late realization. It starts with the assumption that after real events takes place, something suddenly becomes convincing, even obvious (Taleb, 2003).
\end{abstract}

There are five peculiarities of human behaviour bearing responsibility for blindness to Black Swans (Nafday, 2009). In fact, it is the underestimating of the impact of Black Swans, as well as an occasional underestimating of an individual Black Swan (Taleb, 2009). These five human behaviours include narrative and madman fallacy, tunnelling and self-affirmation, as well as innate human nature and silent evidence. The first of the above mentioned problems refers to the narrative fallacy or human weakness emphasized while being interpreted. It also has the tendency of giving certain priority to the stories rather than the real truth or facts (Stojanović, 2011).

Conslusion

Thanks to the behavioural theory of decision making which collected a huge number of experimental evidence, it has been shown that it strictly limits the maximum acheivements of homo economicus, so it can be said that he does not even feel confortable on markets where he used to be earlier. The limitations of this theory are mainly determined by perceptual and process conceptions of rationality. The question is what to do in terms of this disbalance? By creating a hybrid model, it is necessary to make some modifications of the standard economic model in favor of the behavioural one.

The research results, not coinciding with claims and postulates of the traditional economic theory, focus on the fact that during theoretical and empirical studies of economic behaviour more attention should be paid to the methods of forming perceptions and their impact on decision making processes. McFadden (2004) points out that if "cognitive anomalies appearing during cognitive analysis originate from perceptual errors, then the conventional instruments of economic analysis will survive in most cases, although it will be in the form in which the events and experiences from the past are much more important than it is traditionally allowed" (p. 474). Behavioural and financial experts have given their biggest contribution, both theoretical and practical, to the field of financial decision making and financial market roles. However, in some other fields, for example corporate finance, behavioural theoreticians have not shown any particular interest and they have not made any remarkable contribution (Thaler, 1999). It is necessary to emphasize that the critique of behavioural finance is considered to be the critique of the standard financial theory and that it does not have any big status (Bodie, 2009). However, behavioural finance has made much more important contribution in comparison with mere critique of the standard financial theory, which implies their both theoretical and practical values. Yet its limitations can be described in a way that it offers less than a concrete independent scientific discipline providing complete and consistent explanations from the financial sphere. By all odds, it has not been the main inclination of the theory author.

Nevertheless, opting for the final conclusion or judgement, providing that some "superficial" errors caused by partiality, perception or wrong formulation of cognitive tasks are eliminated or accepted, the author of this work holds an attitude that it is possible to systematize a large number of principles, attitudes and preferences a new financial analysis can be built upon, which could be the subject matter for some other work.

On the basis of the previous analyses and reports it can be clearly concluded that system errors and anomalies are more diversiform and manifested which suggests that traditional finance and economics strongholds are additionally threatened, in terms of limitations in explaining economic and financial phenomena. 


\section{LITERATURE}

[1] Anger E., Loewenstein, G. (2007). Behavioural Economics, Gabby D., Thagard P., Handbook of the philosophy of science.

[2] Akerlof, G. , Kranton, R. (2000). Economics and identity, Quarterly Journal of Economics, 115 (3), $715-$ 53.

[3] Akerlof, G. Kranton, R. (2002) Identity and Schooling: Some Lessons for the Economics of Education, Journal of Economics Literature, 40(4), 1167-201

[4] Akerlof, G. Kranton, R. (2005). Identity and the Economics of Organizations, Journal of Economic Perspectives, 19(1), 9-32.

[5] Arijeli, D. (2008). (Ne)logičan izbor.

[6] Belsky, G., Gilovich, T. (2002). Why Smart People Make Big Money Mistakes - and How to Correct Them.

[7] Bodie Z., Kane, A. (2009). Osnovi investicija.

[8] Brunaker, F., Nordqvist, A. (2013). A Performance Evaluation of Black Swan Investments. Bachleor Thesis.

[9] Dobeli, R. (2013), Veština jasnog mišljenja - Pedeset dve greške u mišljenju koje je bolje prepustiti drugima.

[10] Estrada, J. (2009). Black Swans in emerging Markets, Journal of Investing. 18(2), 50-56.

[11] Fehr, E., Gachter, S. (2000). Cooperation and Punishment in Public Goods Experiments, American Economic Review, 90 (4), 980-991.

[12] Frankfurte, G. M., McGoun, E. G. (2000). Market Efficiency or Behavioural Finance: The Nature of the Debate. The Journal of Psychology and Financial Markets,Vol. 1, Nos. 3\&4, 200-210.

[13] Hannerz, U. (1990). Cosmopolitans and locals in world culture, Theory, Culture and Society, 7, p.p. 237-247.

[14] Langer, E.J. (1975). The illusions of Control. Journal of Personality and Social Psychology 32, p.p. 341-353.

[15] Nafday, A. M. (2009). Strategies for Managing the Consequences of Black Swan Events, Leadership and Management in Engineering, 9(4), pp 191-197.

[16] Nofsinger, J. (2002). The Psihology of Investing.

[17] O'Barr, W.M., Conley, J.M. (1992). Fortune and Folly: The Wealth and Power of Institutional Investing.

[18] Quattrone, G.A., Tversky, A. (1984). Causal versus diagnostic contigencies: on self deception and on the voter's illusion, Journal of Personality and Social Psychology, 46, 237-249.

[19] Roll, R. (1986). The Hubris hypothesis of coporate takeovers, Journal of Business, 59, 541-547.

[20] Shaffir, E, Tversky, A. (1992). Thinking through uncerainty: nonconsequential reasoning and choice, Cognitive Psychology, 24, 449-459.

[21] Shiller, R. (2000). Irrational Exuberance.

[22] Sniedovich, M. (2012). Black Swans, New Nostradamuses, Voodoo decision theories, and the science of decision making in the face of severe uncertainty. International Transactions in Operational research, 19(1-2), 253-281.

[23] Stojanović, B. (2011). Dalekosežni uticaj nepredvidivog i neočekivanog, Filozofija i društvo, 22(1), 279-290.

[24] Tahler R. (1999). The End of Behavioural Finance, Financial Analyst Journal. November/December, 12-17.

[25] Taleb, N. N. (2004). Few and Far Between: Black Swans and the Impossibility of Prediction, Change This, 33(4), 1-16.

[26] Taleb, N. N. (2003). The Black Swan: Why Don't We Learn that we Don't Learn.

[27] Taleb, N. N. (2007). The Black Swan: The Impact of the Highly Improbable, Get Abstract.

[28] Taleb, N. N. (2009). Crni labud: Utjecaj krajnje nevjerojatnog.

[29] Vissing-Jorgensen, A. (2004). Perspectives on Behavioural Finance: Does "Irrationality" Disappear with Wealth? Evidence from Expectations and Actions, 32-49.

[30] Tvede, L. (2005). The Psychology of Finance.

[31] Sewell, M. (2010), Behavioural Finance, http://www.behaviouralfinance.net/behavioural-finance.pdf, posećeno 15.6.2016.

[32] Hellmann, A. (2016), The role of accounting in behavioural finance, Journal of Behavioural and Experimental Finance, Volume 9, March, p. 39.-42 
[33] De Bondt,W. i Thaler, R. (1985), Does the stock market overreact?, Journal of Finance, 40, p. $793-808$

[34] Odean, T. (1999), Do investors trade too much?, American Economic Review, 89, p. 1279-1298

[35] Barberis, N. i Thaler, R. (2003), A survey of behavioural finance, in Constantinides, M. Harris, M. \& Stulz, R.M., Handbook of the Economics of Finance, vol. 1B, p. 1053-1123, Elsevier North Holland

Receieved: June 2016.

Accepted: September 2016.

\title{
$1 / 1 / 1 / 1 / 1 / 1 / 1 / 1 / 1 / 1 / 1 / 1 / 1 / 1 / 1 /$ abouthe euthor
}

\begin{abstract}
Milena Vučinić
Milena Vučinić is a master of technical sciences - field of organizational sciences for the financial risk management. She is a licensed broker, dealer, portfolio manager and PR consultant. vucinicm@t-com.me
\end{abstract}

She has fifteen years of work experience on the capital market, she worked as an authorized broker and dealer in Monte Adria Broker Diler - Podgorica, and for the last nine years she has been working as a portfolio manager at Atlas Mont Investment Fund in Podgorica. Apart from that, she also works as

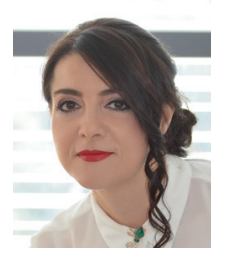
a deputy officer for money laundering prevention.In the period from 2006 to 2009 she worked as an editor of economy programme at Atlas Television, as well as an author and presenter of "Business, money and profit" TV programme where she prepared reports and presented events from Montenegrin stock exchange. Her programme and stock exchange reports were taken and broadcast by a business television Kapital TV

from Zagreb, Croatia. While working she improved her professional knowledge and skills by visiting significant financial institutions and corporations in Europe where she attended numerous seminars and lectures. 
HIIIIIIIIIIIIIIIIIIIIIIIIII

Management 